\title{
ASSOCIATION FORMATION TECHNIQUE IN PRESCHOOL CHILDREN
}

\author{
Gulobod Rakhmatova
}

Master of Preschool Education, Navai State Pedagogical Institute, Uzbekistan, Navai

\section{ABSTRACT}

This article discusses association formation technique in preschool children.

Language is a linguistic structure with a multifaceted complex structure. It is natural for a person to influence the use of language, to try to "express it in their own way." Instead, language is also a powerful force that helps regulate a person's social life. Such a relationship between the language and the person who uses it, of course, does not go unnoticed in the language. One of the methods that serves to determine the richness of the human vocabulary, its formation and development, is the method of associative experiment.

KEYWORDS:- Technique, preschool children, associative experiment

\section{INTRODUCTION}

Language is a linguistic structure with a multifaceted complex structure. It is natural for a person to influence the use of language, to try to "express it in their own way." Instead, language is also a powerful force that helps regulate a person's social life. Such a relationship between the language and the person who uses it, of course, does not go unnoticed in the language. One of the methods that serves to determine the richness of the human vocabulary, its formation and development, is the method of associative experiment.

\section{THE MAIN RESULTS AND FINDINGS}

A number of reasons contributed to the modern study of associations: the emergence and development of structuralism and a comprehensive linguistic description of a significant number of national and rare languages; interest in the national and cultural specifics of linguistic factors and the emergence of new scientific disciplines (psycholinguistics, semiotics, cultural studies, etc.). But, probably, the most significant impulse in the development of associative problems was purely practical needs: the development of new methods of teaching foreign languages, the creation of machine languages, the modeling of the process of generation and perception of speech, interest in the analysis of linguistic consciousness and the construction of models of pictures of the world before representatives of different cultures and social groups. The child learns the world with the help of certain processes taking place in his brain. The main cognitive process is thinking, 
CURRENT RESEARCH JOURNAL OF PEDAGOGICS 2(6): 11-13, June 2021

DOI: https://doi.org/10.37547/pedagogics-crjp-02-06-03

ISSN 2767-3278

(C)2021 Master Journals

\section{Crossref do) 81 Google}

Accepted 04 th June, 2021 \& Published 09' ${ }^{\text {th }}$ June, 2021

which determines a lot in the life of an adult and a child. Associations in a child's life determine his perception of the world, learning. What is associative thinking? The name of this type of thinking speaks for itself. These are the processes of cognition and reflection of the surrounding world, based on associations. A logical question arises: "What are associations?" This is a certain connection between different concepts or representations, which arises when one is aware of any of them. Such a relationship can be normal and logical for one person and absolutely contradictory for another. Associative thinking helps people discover something new, expand the boundaries of knowledge of the world. For example, for one person the word "winter" evokes an associative connection with the cold and fading nature, for another with snowflakes and a snow-covered alley, for a third with his birthday, New Year's holidays. This is how the conceptual series expand, a person learns to think outside the box, creatively. People with well-developed associative-figurative thinking are valued at work, perceive the world in cheerful colours. Therefore, this kind of cognitive process is important to develop from childhood. Classes, types of associations, like all complex scientific concepts, it also has its own classification. Associations are divided according to the following criteria:

- Causal concepts: cold-coat, rain-umbrella;

- Similarity of concepts: dirt - dust;

- Proximity in space and time: TV- remote control, gas-fire;

- The contrast of the qualities of the object: warm - cold, light - dark;

- Generalization: Ali is a brother, a tulip is a mountain;

- Addition: dish - potatoes;

- Subordination of concepts: fruit - watermelon;

- Whole and parts: kindergarden - swing, children's kindergarden - bed;

National and cultural units used to study the associative worldview of preschoolers, words actively used in speech, prove that most children are a reflection of their family and the world around them. They illuminate the family situation, character, attitude of adoptive sisters, friends without any illusions.

In this associative experiment, we used the following associative educational games. According to our national mentality, preschoolers lovingly observe a lamb from a pet. Accordingly, in this game we study the relationship of a child with a lamb.

The game "Our beloved domestic animals". For example, we became lambs. What are the lambs doing? How do they eat? How do they sleep? How do they wash themselves? We transfer the "image of a lamb" to ourselves. That is, her front paws are our hands, we walk on all fours, we eat herbs, our words are mee, mee. We try to convey with the help of them what we want to say.

Game "What? How?" You can use these cards. We just take an object and describe it, trying to name what it looks like in its shape / color / size / function, etc. You can just try to comment on everything on the way home or on a walk more often with the expressions "Oh, what a yellow flower, like the sun", "The wind blows like a hair dryer", "Birds are singing as if just such a song (and singing)", "The shoes are dirty, like the dishes after dinner ", etc. The child will quickly catch up and begin to actively compare, and most importantly, develop associative thinking.

Game: "Chain of associations". Take turns with the child to name the word that "arises" in the head. For example, like this:

Mom: chef 
CURRENT RESEARCH JOURNAL OF PEDAGOGICS 2(6): 11-13, June 2021

DOI: https://doi.org/10.37547/pedagogics-crjp-02-06-03

ISSN 2767-3278

(C)2021 Master Journals

Crossref dof 81 Google

Accepted 04thJune, 2021 \& Published 09th June, 2021

Dad: banker

Mom: shoes

Dad: Boots

Mom: warm

Dad: refrigerator

etc.

While we are playing, we not only develop thinking, but also laugh heartily, because at times, the associations are very funny!

And even one task children perform in different ways - for example, children's associations with the word "spring" were different (summer, sun, butterflies, flowers, birds, buds on trees ...)

In preparing for school, it is very important to help your child develop logical thinking. Very interesting and informative tasks for the development of thinking in children will help you with this. By completing these tasks, your child will learn to compare and reason. Your child will develop logical thinking. Tasks for the development of thinking are very important in preparation for school. It is very good if your child can independently explain his choice when performing tasks for the development of thinking. If your child finds it difficult or gives an incorrect answer, tell him, but don't be completely responsible for him.

In preparation for school, you also need to help your child develop critical thinking. Critical thinking involves the use of the ability to reason. Its essence is to actively learn, not just be a passive receiver of information. People who have developed critical thinking often question ideas and facts, instead of accepting them in their original form. They also try to find out if their ideas, arguments and conclusions are in line with the general system of values, while maintaining an openness to objection and discussion.

\section{Conclusion}

So, the associative thinking of a child cannot function independently to the required degree, he needs the help of adults - parents and teachers. A limited number of associations in thinking in an adult prevents him from solving his problems efficiently and quickly, complicates the development of the child. A child's associative thinking can be stimulated at an early age. But the development process should take place in stages. To do this, it is necessary to acquaint the baby with all the concepts of the environment and the actions that are associated with them. Then the child learns to generalize (for example, the names of different colours in one concept "flowers"), to name, to distinguish.

\section{ReFERENCES}

1. Abramov V.P. The theory of the associative field / Lexicology, phraseology and lexicography of the Russian language: http://netref.ru/leksikologiya-frazeologiyai-leksikografiya-russkogo-yazika-te.html

2. Alferova Yu.I. Professionally marked components of linguistic consciousness, represented by units of the native and studied languages: Dis. ... Cand. philol. sciences. - Omsk, 2005 -- 220 p.

3. Belyanin V.P. Psycholinguistics. Textbook. M .: Flinta, 2003 .-- 232 p.

4. Lutfullaeva D., Davlatova R., Tojiboev B. Associative Dictionary of the Uzbek Language. -Tashkent, 2019. 